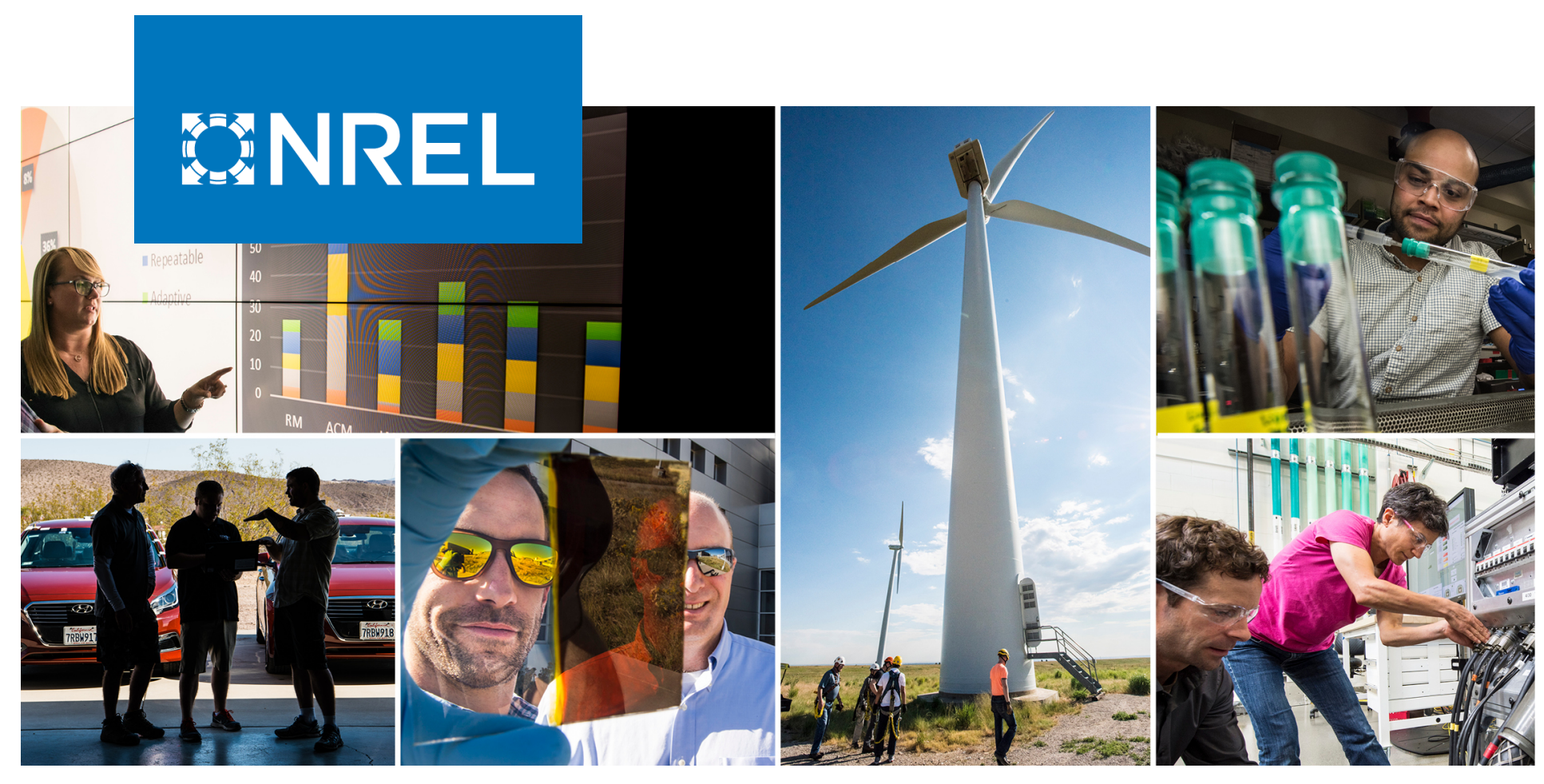

\title{
Maximizing Distributed Energy Resource Value for All Stakeholders
}

Jessica Lau, Elaine Hale, and Jenny Heeter

NREL is a national laboratory of the U.S. Department of Energy

Office of Energy Efficiency \& Renewable Energy

Operated by the Alliance for Sustainable Energy, LLC

This report is available at no cost from the National Renewable Energy Laboratory (NREL) at www.nrel.gov/publications.
Technical Report

NREL/TP-6A20-76926

September 2020 


\title{
FNREL
}

\section{Maximizing Distributed Energy Resource Value for All Stakeholders}

\author{
Jessica Lau, Elaine Hale, and Jenny Heeter
}

\section{Suggested Citation}

Lau, Jessica, Elaine Hale, and Jenny Heeter. 2020. Maximizing Distributed Energy

Resource Value for All Stakeholders. Golden, CO: National Renewable Energy

Laboratory. NREL/TP-6A20-76926. https://www.nrel.gov/docs/fy20osti/76926.pdf.

NREL is a national laboratory of the U.S. Department of Energy Office of Energy Efficiency \& Renewable Energy Operated by the Alliance for Sustainable Energy, LLC

This report is available at no cost from the National Renewable Energy Laboratory (NREL) at www.nrel.gov/publications.

Contract No. DE-AC36-08GO28308
Technical Report

NREL/TP-6A20-76926

September 2020

National Renewable Energy Laboratory 15013 Denver West Parkway Golden, CO 80401

303-275-3000 • www.nrel.gov 


\section{NOTICE}

This work was authored by the National Renewable Energy Laboratory, operated by Alliance for Sustainable Energy, LLC, for the U.S. Department of Energy under Contract No. DE-AC36-08GO28308. This work was supported by the Laboratory Directed Research and Development Program at NREL, as well as the U.S. Department of Energy Office of Energy Efficiency and Renewable Energy Office of Strategic Programs. The views expressed herein do not necessarily represent the views of the DOE or the U.S. Government.

This report is available at no cost from the National

Renewable Energy Laboratory (NREL) at

www.nrel.gov/publications.

U.S. Department of Energy (DOE) reports produced after 1991 and a growing number of pre-1991

documents are available

free via www.OSTI.gov.

Cover Photos by Dennis Schroeder: (clockwise, left to right) NREL 51934, NREL 45897, NREL 42160, NREL 45891, NREL 48097, NREL 46526 .

NREL prints on paper that contains recycled content. 


\section{Acknowledgments}

The authors would like to thank all the participants in the Maximizing Distributed Energy Resource Value for All Stakeholders workshop held at the National Renewable Energy Laboratory (NREL) in Golden, Colorado, May 29-30, 2019, for their active participation and willingness to engage in candid conversation (Table A-1). In particular, we would like to thank Stewart Ramsay for his technical expertise and advice on workshop design and stakeholder engagement.

Table A-1. Industry Workshop Participants

\begin{tabular}{|l|l|}
\hline External Participant & Organization \\
\hline Pablo Bauleo & Fort Collins Utilities \\
\hline Steve Beuning & Holy Cross Energy \\
\hline Kristen Brown & Exelon (formerly) \\
\hline Samuel Golding & Community Choice Partners, Inc. \\
\hline Marissa Hummon & Utilidata \\
\hline Richard McAllister & Western Interstate Energy Board \\
\hline George McGuirk & Xcel Energy \\
\hline Brendan Owens & U.S. Green Building Council \\
\hline James Pigeon & New York ISO \\
\hline Josh Radoff & WSP \\
\hline Stewart Ramsay & Vanry Associates \\
\hline Tim Rehder & Environmental Protection Agency \\
\hline Janea A. Scott & California Energy Commission \\
\hline Lane Smith & University of Washington \\
\hline Lindsey Stegall & Colorado Energy Office \\
\hline Greg Vaudreuil & Mosaic Power \\
\hline Frédéric Wauquiez & General Electric (GE) Renewables \\
\hline Henry Yoshimura & ISO New England Inc. \\
\hline
\end{tabular}

This event was only possible because of support from our NREL colleagues who assisted with workshop planning and facilitation. We would like to thank Mark O'Malley for helping conceptualize and secure laboratory funding for the workshop. Bryan Palmintier and Monisha Shah provided essential assistance with workshop planning, including outreach to prospective invitees. We would also like to thank Gian Porro and Elizabeth Doris for their early advisory support. We are especially grateful to all of the NREL facilitators (Table A-2) for their leadership and assistance during the workshop. 
Table A-2. NREL Workshop Facilitators

\begin{tabular}{|l|l|}
\hline Name & NREL Center \\
\hline Dylan Cutler* & Integrated Applications Center \\
Elaine Hale ${ }^{\dagger}$ & Strategic Energy Analysis Center \\
Jenny Heeter* & Strategic Energy Analysis Center \\
Jessica Lau & Strategic Energy Analysis Center \\
D-Y Lee & Transportation and Hydrogen Systems Center \\
Adarsh Nagarangan & Power Systems Engineering Center \\
Mark O'Malley & Energy Systems Integration Directorate (formerly) \\
Bryan Palmintier* & Power Systems Engineering Center \\
Shanti Pless & Buildings and Thermal Systems Center \\
Monisha Shah* & Strategic Energy Analysis Center \\
Yinong Sun & Strategic Energy Analysis Center \\
\hline \multicolumn{2}{|c|}{${ }^{*}$ Discussion Group Leader } \\
& ${ }^{\dagger}$ Workshop Coordination
\end{tabular}

We would like to thank Nongchao Guo for assisting with literature review, and Mike Meshek for editing support. We would like to also thank reviewers Pablo Bauleo (Fort Collins Utilities), Justin Hill (Southern Company Services), Sergio Islas (Southern California Edison), Ted Ko (Stem, Inc.), Lane Smith (University of Washington), Henry Yoshimura (ISO New England), Jaquelin Cochran, Dylan Cutler, and Mark O’Malley (NREL) for engaging with this material post-workshop. 


\section{List of Acronyms}

CHP

DER

combined heat and power

HVAC

LCOE

NOPR

NREL

PPA

PV

distributed energy resource

heating, ventilation, and air conditioning

levelized cost of energy

notice of proposed rulemaking

National Renewable Energy Laboratory

power purchase agreement

photovoltaics 


\section{Executive Summary}

\section{How to Maximize the Value of \\ Distributed Energy Resources (DER) \\ for all Stakeholders}

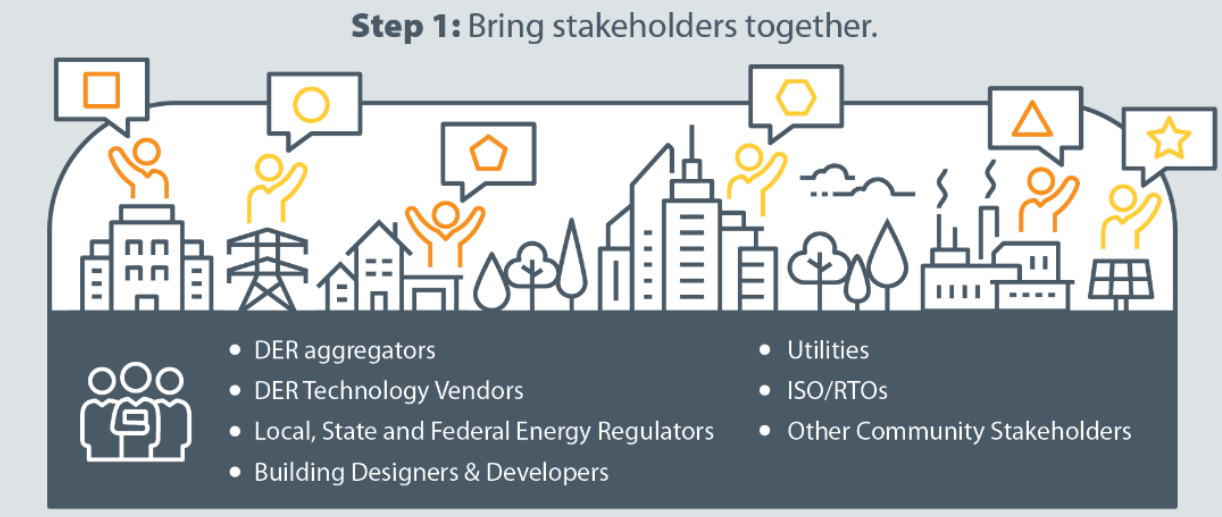

Step 2: Identify questions addressing stakeholders' diverse needs.

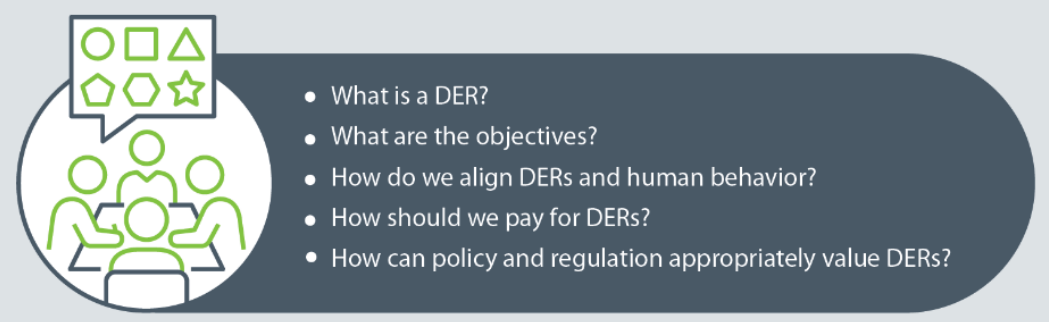

Step 3: Make an action plan to resolve stakeholder questions, meet needs, and maximize DER value.

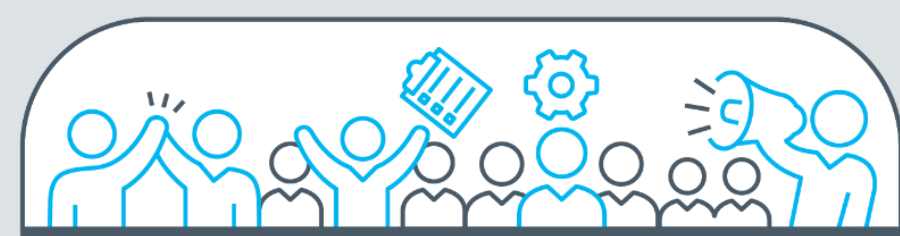

口 Encourage experimentation by actors with more independence

口 Create an integration road map

- Communicate grid and end-user needs and capabilities

$\square$ Develop more expansive pilot projects with innovative market structures

Bulleted questions and action steps were identified by stakeholders at a distributed energy resources engagement workshop hosted by the National Renewable Energy Laboratory in May 2019.

Figure 1. Process for maximizing DER value for all stakeholders

Maximizing DER value for all stakeholders required bringing together the right people, asking the right questions, and creating an action plan that reflects people's needs. 


\section{Table of Contents}

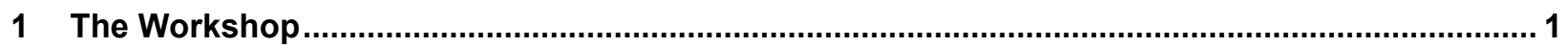

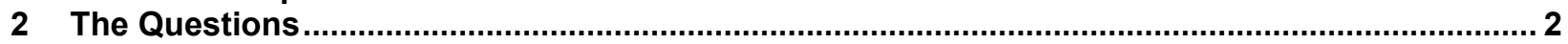

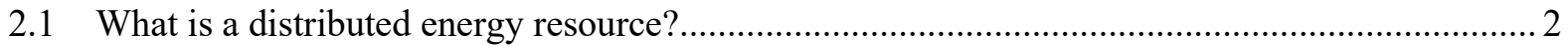

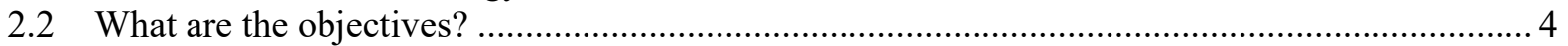

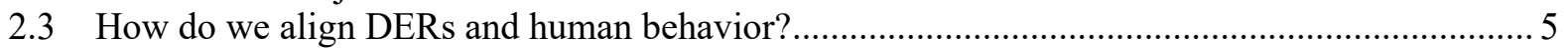

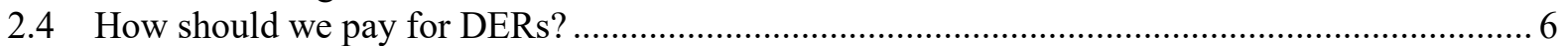

2.5 How can policy and regulation appropriately value DERs? .............................................. 7

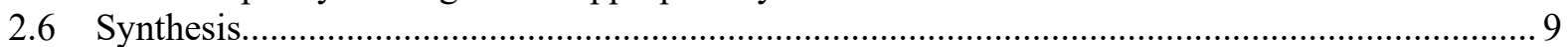

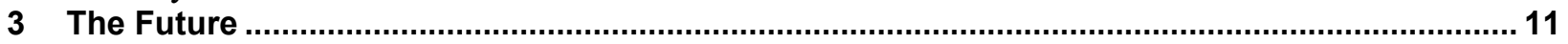

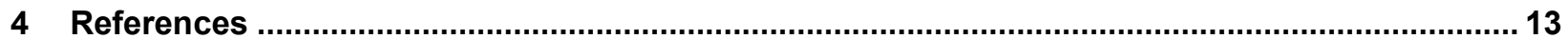




\section{List of Figures}

Figure 1. Process for maximizing DER value for all stakeholders ....................................................... vi

\section{List of Tables}

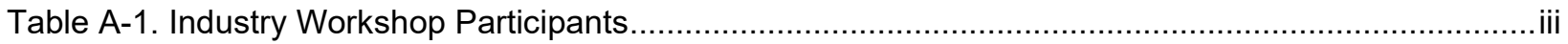

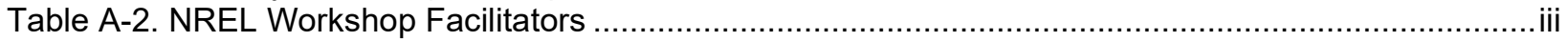




\section{The Workshop}

As NREL staff explore technical aspects of the integration of distributed energy resources (DERs), we also wonder about the interaction of these technologies with the many stakeholders that are involved with DERs. And in pursuit of integrated and optimized power systems, these stakeholders must continue to discuss and determine whether and how to utilize and value DERs. To better understand these aspects of the DER landscape, NREL researchers assembled a diverse group of external stakeholders in May 2019 for a workshop titled Maximizing Distributed Energy Resource Value for All Stakeholders. To ensure a wide range of key perspectives would be present and able to encounter each other in a collaborative setting, we invited power sector representatives, state energy regulators, policymakers, DER aggregators and technology vendors, the green building community, and the research community. The workshop's primary goal was to advance industry understanding of how to approach and value DERs by attending to all key perspectives.

Over the one and a half days of the workshop, nearly 30 participants conversed via participant presentations, brainstorming, social interaction, guided discussions, and consensus building. The core of the workshop was a series of breakout sessions during which participants stepped through the processes of getting to know one another's perspectives; formulating, elaborating, and discussing questions about DERs; and finally proposing some next steps for discerning the value of DERs in current and future power systems.

Much workshop time was spent gaining an understanding of each other's terminology, objectives, and perspectives. The common understanding so-established was the foundation needed before more complex discussion could be had. By the end of the workshop, participants articulated four high-level next steps that would support the development of a more complete understanding of the value of DERs at scale. These steps or actions could provide the information needed to ensure DER integration ultimately provides value to all stakeholders.

This report summarizes what the workshop participants as a whole articulated about DERs, as refined by the authors of the report through the writing and review process. 


\section{The Questions}

During the breakout sessions, participants articulated and discussed their questions about DERs, and they then spent time organizing their questions into common themes. Which questions are similar? Which are most important? Which ones are answerable, and which are inherently ambiguous? After reflecting on the breakout groups' DER questions and reporting artifacts, as well as notes on and recollections of whole-workshop and smaller-group discussions, the authors identified five lines of questioning generally held in common across the workshop:

1. What is a distributed energy resource?

2. What are the objectives?

3. How do we align DERs with human behavior?

4. How should we pay for DERs?

5. How can policy and regulation appropriately value DERs?

We describe each question in the subsections below. The reader may notice that the top-line questions tend to be ambiguous. The discussion that follows each question attempts to untangle the different strands of understanding represented by different perspectives that, when fit into a single question, together sound ambiguous. We believe the ambiguity reflects the inherent complexity of DER technologies. And we hope the discussion provides some common vocabulary, meaning, and understanding.

\subsection{What is a distributed energy resource?}

DERs, which have been integrated into residential, commercial, and industrial buildings, ${ }^{1}$ are a key aspect of grid policy, ${ }^{2}$ long-term grid planning, ${ }^{3}$ and grid operations. ${ }^{4}$ However, it is funny but true that there is no consistent definition of DERs across all industries and stakeholders.

As this workshop's goal was to advance understanding of how to maximize the value of DERs to all stakeholders, participants soon keyed into the lack of common understanding and definition of DERs. For the workshop discussion, participants agreed to define DERs as being inclusive of all technologies connected through the distribution power system that provide electricity supply (e.g., generate power that supplies the grid or offsets local load) or modify electricity use to provide grid services (e.g., change baseline demand patterns to better align with power supply). Examples of DERs include solar photovoltaics (PV), combined heat and power (CHP) systems, behind-the-meter batteries, electric vehicle batteries, and demand response programs. Once this basic DER definition was established, participants did not spend additional time addressing the

\footnotetext{
${ }^{1}$ Barbose et al., "Tracking the Sun: Pricing and Design Trends for Distributed Photovoltaic Systems in the United States, 2019 Edition"; ICF Inc. and DOE, "U.S. DOE Combined Heat and Power Installation Database"; Wood Mackenzie P\&R and ESA, "U.S. Energy Storage Monitor: 2018 Year in Review and Q1 2019 Full Report."

${ }^{2}$ CPUC, “California's Distributed Energy Resources Action Plan: Aligning Vision and Action”; Newcomb et al., "Distributed Energy Resources"; APPA, "Distributed Energy Resources Issue Brief”; DOE, "Renewable Energy: Distributed Generation Policies and Programs."

${ }^{3}$ NERC, "2019 Long-Term Reliability Assessment”; FERC, "Distributed Energy Resources: Technical Considerations for the Bulk Power System."

${ }^{4}$ NYISO, "Distributed Energy Resources Roadmap for New York’s Wholesale Electricity Markets."
} 
inclusion or exclusion of specific technologies for the purposes of the workshop. However, in each of the participant's domains, they would generally define DERs somewhat differently.

As exemplified by the Federal Energy Regulatory Commission's (FERC's) recent history, it can be challenging to operationalize broad definitions of DER in large, multilayered power systems. Current demand response policy, as described in FERC Order $745^{5}$ and upheld in FERC v. Electric Power Supply Assn ${ }^{6}$ requires independent system operators (ISOs) and regional transmission organizations (RTOs) to pay the locational marginal price (LMP) for load reductions if a net benefits test is satisfied. This framework enables demand response to participate in the wholesale market on the supply side, but only as a load reduction resource. In 2018, FERC acknowledged that this is an inadequate description of demand response and DER capabilities, as it does not enable centralized scheduling of the load increases that may be necessary to prepare for or recover from a load reduction event. ${ }^{7}$ Subsequently, FERC Order 841 mandated ISOs and RTOs to accommodate the physical and operational characteristics of storage resources 100 kilowatts and larger in their capacity, energy and ancillary service markets. Full DER reform along similar lines but for a wider variety of resources has been delayed - the 2018 conclusion that the commission had insufficient information to proceed with DER rulemaking because of unresolved jurisdictional, operational, aggregation, ratemaking, and other issues ${ }^{8}$ has only been confirmed by the case against Order 841 , although its resolution in FERC's favor ${ }^{9}$ may encourage follow-on reform efforts.

Other forms of DER participation (e.g., to provide energy arbitrage or regulation reserve) have been achieved ${ }^{10}$ or piloted, ${ }^{11}$ but typically on a case-by-case, technology-specific basis. Thus, a consistent definition has not been needed to continue integrating DERs, but workshop participants questioned what opportunities have been missed because of this lack of clarity. The participants identified the following questions as needing more discussion across multistakeholder groups:

- At what point does a customer device become a DER? If a device or program is technically capable of providing grid services, does that qualify it as a DER? Or should there be minimum utilization thresholds?

- Instead of having a DER definition that lists specific technologies, would it be more effective to determine technology-agnostic grid service definitions, interconnection standards, and communication protocols? If so, which characteristics of DERs would

\footnotetext{
${ }^{5}$ FERC, "Demand Response Compensation in Organized Wholesale Energy Markets [Docket No. RM10-17-000; Order No. 745]."

${ }^{6}$ FERC v. Electric Power Supply Assn.

${ }^{7}$ FERC, "Electric Storage Participation in Markets Operated by Regional Transmission Organizations and Independent System Operators [Docket Nos. RM16-23-000; AD16-20-000; Order No. 841]."

${ }^{8}$ FERC, "Participation of Distributed Energy Resource Aggregations in Markets Operated by Regional

Transmission Organizations and Independent System Operators; Notice Inviting Post-Technical Conference Comments."

${ }^{9}$ Wilkins, National Association of Regulatory Utility Commissioners v. Federal Energy Regulatory Commission.

${ }^{10}$ McAnany, "2019 Demand Response Operations Markets Activity Report: April 2020.”

${ }^{11}$ BPA, "CTA-2045 Water Heater Demonstration Report Including A Business Case for CTA-2045 Market Transformation"; Ardani, O’Shaughnessy, and Schwabe, "Coordinating Distributed Energy Resources for Grid Services: A Case Study of Pacific Gas and Electric."
} 
need to be explicitly accounted for in those processes to ensure lower barriers to participation?

- Who is responsible for the control and performance of DERs? Does the answer to that question depend on which grid service is being provided and to whom? Is it ever the case that a DER providing a service to one grid operator (e.g., distribution system operator, load serving entity, or independent system operator) creates extra costs for another?

- What are the appropriate levels of DER aggregation? Are DER owner, operator, or electrical network characteristics most important when answering that question? Should DERs be partitioned by technology type?

\subsection{What are the objectives?}

DERs are inherently subject to multiple objectives. Every DER has a primary purpose (e.g., energy generation [PV], transportation [electric vehicle], heating or cooling [HVAC equipment], production of goods or services [commercial \& industrial operations]); and that primary purpose likely drives the adoption decision. For example, people do not purchase PV systems to provide ancillary services to an independent system operator, nor do they buy electric vehicles to help their local utility avoid power outages. That being said, grid services from DERs are possible to the extent that a DER has extra capacity that can be dedicated to a secondary purpose. Many commercial enterprises and industrial processes are an order of magnitude more valuable than their energy inputs, ${ }^{12}$ but there may still be sufficient scheduling flexibility (e.g., for an operation not running at full capacity) or low-impact operational changes (e.g., dimming lights and moderating temperature set points) that enable demand response program participation. Thus, the primary purpose is always prioritized, but a DER may possess additional flexibility that could be harnessed to improve grid operations without detrimentally impacting that primary function. Extra income from providing a grid service may also further incent adoption.

Also, the power system is designed and operated with multiple objectives. State and federal regulators have a mandate to ensure affordability and reliability; and, depending on jurisdiction, they may be responsible for implementing other policy goals, such as environmental protection or open access to transmission and wholesale markets. Utilities respond to regulatory mandates and act in the interest of their owners, which may consist of shareholders, cities, or co-op members. Citizens express their multifaceted desires through various governance processes, including voting. Various corporations (e.g., utilities and energy technology providers) and interest groups (e.g., oil and gas industry, and environmental organizations) also engage in lobbying, advertising, and other forms of persuasion. All these rules and behaviors express various objectives and preferences, which meld together to inform power grid investments and operations. Thus, integrating inherently multi-objective DERs with the multi-objective power system is necessarily complex, requires balancing many objectives, and raises many questions:

- To what extent are DER owners willing to provide grid services?

- What factors influence that willingness, both overall and day-to-day?

\footnotetext{
${ }^{12}$ Sullivan, Vardell, and Johnson, "Power Interruption Costs to Industrial and Commercial Consumers of Electricity"; Russell, "Efficiency and Innovation in U.S. Manufacturing Energy Use”; Bohi, "On the Macroeconomic Effects of Energy Price Shocks.”
} 
- Does the potential for a DER technology to be a grid asset automatically imply it should be included in grid planning?

- If DERs are used simply to lower grid costs, are those benefits shared fairly? Should we explicitly use DERs to achieve longer-term societal goals? If yes, what are they?

- If longer-term goals are chosen well and expressed clearly, would it be easier to elicit, use, and equitably share the benefits of demand-side flexibility?

Mid-workshop, participants were hopeful that in some jurisdictions, or as a component of some pilot programs, it might be possible to organize DER participation around one or just a few highlevel objectives (e.g., minimize greenhouse gas emissions while maintaining grid reliability). By the end of the workshop, participants still held that hope, but they also recognized that the picture is likely to remain complex, because all stakeholders involved in integrating DERs have their own perspective that necessarily involves a mixture of self-, corporate-, and society-focused needs and desires.

\subsection{How do we align DERs and human behavior?}

Utilities have historically had a unidirectional relationship with customers, with consumers paying for electricity and utilities providing it. Current technology and culture is changing that relationship. People expect more choice in electricity supply (e.g., net-metered PV, community solar, retail tariffs, and provider options) and more visibility and control over their energy-using appliances (e.g., smart-phone connected thermostats, electric vehicle charging options, commercial and industrial energy management systems, and other operational automation). These expectations bring a new paradigm in which legacy grid planning processes can fall short in anticipating emerging demand-side challenges and opportunities.

The grid operator would like to use all cost-effective resources, including DERs, to meet grid needs. But utility customers would like to use DERs to meet their own needs first, and only provide grid services with leftover capability (e.g., only allow modified air conditioner operations if my home will still stay sufficiently cool). Perhaps these and similar reasons are why demand response programs are generally assumed to be unable to achieve majority participation (e.g., the 2025 California Demand Response Potential Study assumes maximum achievable participation rates of less than $40 \%$ across all customer types based on historical demand response program data. ${ }^{13}$ Given the increasing numbers of DERs and the increasing need for grid flexibility, workshop participants wondered to what extent people's interactions with the grid could be streamlined to elicit much greater participation in achieving mutually beneficial results.

Thinking economically, workshop participants also wondered whether electricity users and grid owners, operators, and regulators could communicate through price signals. Although the participants acknowledged that economic incentives are only one part of the alignment required to achieve a common goal of DERs providing grid services, they also recognized that prices could provide clear, communicable signals. However, there can be significant overhead to

\footnotetext{
${ }^{13}$ Alstone et al., "2025 California Demand Response Potential Study: Charting California's Demand Response Future (Phase 2 Appendices A).”
} 
designing and operating price-formation processes, ${ }^{14}$ and frequently-changing prices have modest impacts if the mechanisms for response are insufficient. ${ }^{15}$

Recognizing that prices often reflect short-term, rather than long-term, needs and desires, perhaps there are simpler ways to align long-term objectives and make it easy for individuals to make decisions to contribute towards the flexible grid of the future. The participants identified the following questions as needing more discussion across multi-stakeholder groups:

- Can grid integration hardware and software be present and easily activated at the time of purchase to enable customer interactions with the grid?

- Would customers prefer a flat, constant bill similar to that of a cell-phone plan? Could such plans be structured to incent utilities to assume demand-side responsibility (e.g., energy efficiency and flexibility services) and for customers to yield some control?

- Can prices be structured or customized to contain sufficient information about grid needs? What price-like information is available for informing long-term decision making? Will people respond to those signals if we construct them?

- How can we better understand and respond to what customers need and want from the grid?

\subsection{How should we pay for DERs?}

Workshop participants had questions about how DERs should be paid for, especially because DERs can provide multiple benefits. And participants recognized that this question really comes in two parts that may have interrelated answers: (1) How should DER technologies be paid for and (2) how should grid services provided by DERs be paid for? Ultimately, because there are multiple coherent ways to answer those interrelated questions, DERs may be paid for in multiple ways, depending on market, societal and other objectives.

Historically, upfront DER investments have been made by end users like residential homes and commercial facilities. Those end users then receive the primary benefits of local DER operation as well as compensation for the energy, capacity, or other grid services their DERs provide. However, new business models have emerged that help overcome challenges of having end users finance DERs (e.g., power purchase agreements and utility-owned DERs). With third-party financed systems, end users may take on less risk, for example, by paying not only for output (kilowatt-hours) but also for financing, which lowers their overall return on their project investment. It has been found that residential solar loans were 19\%-29\% lower on a levelized cost of energy (or LCOE) basis than a power purchase agreement (PPA) because PPA transactions have both a higher cost of capital for the sponsor and tax equity. ${ }^{16}$ Interestingly, as

\footnotetext{
${ }^{14}$ Holland and Mansur, "The Short-Run Effects of Time-Varying Prices in Competitive Electricity Markets"; Roozbehani, Dahleh, and Mitter, "Volatility of Power Grids Under Real-Time Pricing."

${ }^{15}$ Faruqui, Sergici, and Sharif, "The Impact of Informational Feedback on Energy Consumption-A Survey of the Experimental Evidence"; Gyamfi, Krumdieck, and Urmee, "Residential Peak Electricity Demand ResponseHighlights of Some Behavioural Issues."

${ }^{16}$ Feldman and Lowder, "Banking on Solar: An Analysis of Banking Opportunities in the U.S. Distributed Photovoltaic Market."
} 
the costs of solar decline, the percentage of third-party-owned residential systems is starting to decline. ${ }^{17}$

Examples of how DER resources are paid for could include (1) utility-owned assets paid for in the utility's rate base, (2) privately owned assets partially paid for by end users and partially paid for by utility incentives or rebates, and (3) privately owned or utility-owned assets compensated via a competitive market mechanism. If a market mechanism were to be created, participants would be interested in understanding how that mechanism could be structured to send the right economic signals to potential DER owners.

Workshop participants questioned how new business models could be developed, and relatedly, who should make project investments and take on the related risk. They also noted that different business models may be needed for different sectors; for example, building owners or operators may be interested in hosting DERs that can provide grid services, but their needs are dependent on the availability of controls and communications technology, as well as properly aligned incentive structures. If the utility does not provide the right incentive or technology is not available off the shelf, it may be that an aggregator could step in to bridge the gap. But that represents yet another business model that must be aligned to support this type of investment. Counting the building owner, a DER technology, additional communications or control technology, an aggregator, and a utility, we have quickly listed at least five different business models that must be aligned to achieve the common objective of enabling DER capacity.

Though the workshop participants did not have many answers to the questions raised in this area, they did recognize the importance of fairly allocating costs, benefits, and risks. For example, the costs associated with enabling grid services from DERs could be aligned with the party receiving the most benefits. And, similar to regulators' goals of ensuring just and reasonable rates, the hope would be that DER owners and nonowners would both benefit from lower grid costs enabled by DER participation in grid operations.

\subsection{How can policy and regulation appropriately value DERs?}

Policy and regulation can either support or hinder the appropriate valuation and integration of DERs. Participants noted that DER technology development is moving rapidly, and that policy and regulation have been a champion of DERs but in many cases have not responded quickly enough to support this rapid transition, or they may not be holistic enough. ${ }^{18}$ Regulatory delays and outdated policy frameworks impact the speed at which businesses can deploy new technologies.

Policy and regulation have a variety of impacts on DER valuation, including impacts on:

1. Programs and Funding: Policymakers can establish policies and programs to provide additional funding for DER technologies. For example, California's California Electric Vehicle Infrastructure Project (CALeVIP) provides incentives for publicly accessible

\footnotetext{
${ }^{17}$ Feldman, Zwerling, and Margolis, "Q2/Q3 2019 Solar Industry Update.”

${ }^{18}$ For example, a policy may address a narrow issue such as eligibility in an existing grid services program, but not address reforms needed to enable grid service business models.
} 
electric vehicle transportation infrastructure. Revenue streams for policy initiatives such as this may be difficult to identify in some states; California has used more than $\$ 1.2$ billion in revenue from the state's carbon cap-and-trade program to fund low carbon transportation investments such as CALeVIP over the past five years ${ }^{19}$

2. Compensation Frameworks: Policymakers can also require utility regulators to investigate how DERs should be compensated for the services they provide. For example, New York has attached a compensation framework to the value that DERs can provide. Instead of a retail rate credit as seen in net metering frameworks, New York developed a Value of Distributed Energy Resources compensation framework that provides distributed generators varying compensation levels depending on the actual benefits they provide (e.g., energy, capacity, environmental, demand reduction, and locational system relief values). ${ }^{20}$

3. Participation in Existing Markets: Existing market frameworks may not allow DERs at all, or they may restrict their eligibility. For example, Mosaic Power had to work with PJM Interconnection directly for more than a year to become an approved market participant offering regulation reserve capacity based on their hot water heater control and aggregation technology.

Participants also asked the following related questions that warrant further discussion:

- Who gets to set policy and regulate DER integration? The multiple values that DERs can provide may fall under different regulatory jurisdictions, potentially creating complications as to who regulates which component of DER value.

- How can policy and regulation be an enabler of DER valuation, integration, and new business model development? How can policymakers and regulators be more proactive in anticipating the services that DERs could provide, while ensuring reliability and using resources effectively?

- Is there an alternative to regulatory reform when it cannot respond rapidly enough? For example, participants discussed the potential for community choice aggregation and municipal utilities to provide more rapid reforms. ${ }^{21}$

Ultimately, how DER resources will be valued will be determined by public policy programs, funding mechanisms, and public or private compensation frameworks.

\footnotetext{
${ }^{19}$ Scott, "California Electric Vehicle Vision."

${ }^{20}$ New York Department of Public Service. 2017. CASE 15-E-0751. Accessed September 12, 2019: http://www3.dps.ny.gov/W/PSCWeb.nsf/All/8A5F3592472A270C8525808800517BDD?OpenDocument.

${ }^{21}$ Community choice aggregation (CCA) allows local governments to aggregate electricity loads of residential, and in some cases commercial, customers to collectively procure electricity as a bulk purchaser through an alternative electricity supplier.
} 


\subsection{Synthesis}

Many DERs are being adopted for various reasons, most of which are customer-focused rather than grid-operator focused. Some DER adoption choices are motivated by non-energy factors. ${ }^{22}$ In the meantime, variable generation is increasing and power systems may require additional balancing and integration services. ${ }^{23}$ The ability to understand the potential value of DERs in supporting a power system transformation involves a multiplicity of stakeholders, each with its own objectives: the power sector, state energy regulators and policymakers, DER aggregators and vendors, the green building community, the wider research community, and utility customers.

Workshop participants representing these stakeholder groups were interested in understanding what services DERs could provide, when they could provide those services, and how those services would be valued. Several complexities and structural barriers make it difficult to satisfactorily answer these questions:

1. Currently, the most consistently valuable grid services are capacity, energy, and transmission. For example, in the ISO New England and PJM Interconnection regions, energy, capacity, and transmission market settlements represented more than $95 \%$ of all market settlements in $2017 .{ }^{24}$ These bulk-level markets are generally separated from DERs physically by distribution systems and administratively by retail tariffs. Because retail tariffs typically do not track wholesale tariffs in real time or even near real time, DERs can be left with imprecise market signals. Some large customers are advocating for retail energy rates that track wholesale energy rates so they can invest in renewable resources that sell into wholesale markets and receive payments that track their retail energy rates. ${ }^{25}$

2. Though there is wholesale market and vertically integrated utility experience with demand response integration, demand response programs tend to be used to fill short-term grid needs. In these cases, the experience gained by establishing demand response programs may be quickly lost if new supply-side assets are brought on to meet those grid needs in the long term. ${ }^{26}$

3. State policy and regulations sometimes require energy efficiency, demand response, and/or non-wires alternatives to be implemented, but resource planners and consumer adopters exchange insufficient information to enable comprehensive long-term planning that effectively balances everyone's objectives. Examples of such information includes robust information on customer needs and behavior, and timely and digestible information on longterm grid service needs.

4. For DERs to provide grid services, several communication issues need to be resolved. Energy consumers do not know what the grid needs now, or what it will need in 3 or 10

\footnotetext{
${ }^{22}$ Kellison et al., "Grid Edge Quarterly Executive Briefing: Q1 2020."

${ }^{23}$ Cochran et al., "Flexibility in 21 st Century Power Systems."

${ }^{24}$ Denholm, Sun, and Mai, "Introduction to Grid Services: Concepts, Technical Requirements, and Provisions from Wind."

${ }^{25}$ Heeter, Cook, and Sauer, "Existing and Potential Corporate Off-Site Renewable Procurement in the Southeast."

${ }^{26}$ Hale et al., "Potential Roles for Demand Response in High-Growth Electric Systems with Increasing Shares of Renewable Generation"; PJM Interconnection, "Demand Response Strategy."
} 
years; and of course, they may not need to know those things. However, they may prefer options that support grid flexibility whenever they buy a water heater, or design a building, or decide to install a solar-plus-storage system if those options are cost-effective and clearly explained. Conversely, power system planners and operators have only partial visibility into energy consumers' potential flexibility in using and providing energy.

Making progress in determining and potentially unlocking the value of DERs to all the relevant stakeholders likely involves making progress in one or more of these areas. 


\section{The Future}

Though massive changes are happening in the energy sector, many workshop participants thought that changes were not happening quickly enough. The abundance of questions but lack of answers points to a need for more information and highlight that DERs may have different grid services values, as not every DER technology can provide grid value in every location. To more quickly identify what works and what does not, workshop participants identified four common themes for next steps:

1. Participants identified immediate next steps that could be taken given the current regulatory and market structures in the United States. These are items that could be accomplished relatively easily and in a short time frame. Some actions could be taken by actors with more independence, such as municipal utilities, DER aggregators, and district- or community-level mixed-use developments. Municipal utilities in some cases have more flexibility than investor-owned utilities to create new rate structures and market mechanisms. DER aggregators, within the current structure, could continue to work with regional transmission organizations and independent system operators, and with utilities to ensure their technologies are eligible to provide grid services. And building developers, when creating new districts collaboratively with community stakeholders, could ensure they consider participating in any existing and possible future new programs, working though their utility and/or a DER aggregator.

2. Because some jurisdictions have moved more quickly than others to integrate DERs, participants saw value in documenting that progress and creating an integration road map for other jurisdictions. Pilot programs in some areas have been able to test new technologies, rate structures, incentives, and other items; the learnings from those pilot programs should be either incorporated into additional pilot projects or transferred over to the implementation stage.

3. Better connections need to be made between grid and end-user needs and capabilities. Some participants thought that technical communication between devices and grid operations was well-enough developed while others thought there was more need for common standards and metrics to better facilitate two-way and multiway communication. In general though, workshop participants saw a need to better connect grid needs (e.g., services) and characteristics (e.g., time-varying costs, dispatch stack, and emissions) with stakeholders (e.g., state policymakers and regulators, building developers, technology developers, and DER aggregators) who help reflect and meet people's energy needs and desires. There was a consensus that individual utility customers do not need to know grid needs or characteristics in detail; however, appropriate mechanisms need to be in place to incent end-user decisions that support grid needs when appropriate. For example, building developers may be interested in minimizing greenhouse gas emissions by the utility sector, but if they do not receive economic or other signals containing the requisite information (i.e., carbon intensity of electricity at different, including future, times), they are unlikely to take action. 
4. There is a need for larger, more expansive pilot projects and market structures.

Participants noted that new kinds of programs and markets are needed to move beyond minimal-risk technology tests and control demonstrations. Workshop participants would like to see new kinds of larger-scale pilot programs and transitions away from individual programs to creating markets. Where pilot programs are still needed, they could be larger-scale and broader in scope-involving multiple stakeholders, multiple technologies, and more monetary risk than is typical. That is, pilot programs could shift from testing new technologies, incentives, and rules to creating new market structures. 


\section{References}

Alstone, Peter, Jennifer Potter, Mary Ann Piette, Peter Schwartz, Michael A. Berger, Laurel N. Dunn, Sarah J. Smith, et al. "2025 California Demand Response Potential Study: Charting California's Demand Response Future (Phase 2 Appendices A).” Lawrence Berkeley National Laboratory, March 1, 2017.

https://www.cpuc.ca.gov/WorkArea/DownloadAsset.aspx?id=6442452699.

APPA. "Distributed Energy Resources Issue Brief." American Public Power Association, January 2020.

https://www.publicpower.org/system/files/documents/Distributed\%20Energy $\% 20$ Resources $\% 20$ -\%20January\%202020.pdf.

Ardani, Kristin, Eric O’Shaughnessy, and Paul Schwabe. "Coordinating Distributed Energy Resources for Grid Services: A Case Study of Pacific Gas and Electric." Technical Report. Golden, CO: National Renewable Energy Laboratory (NREL), November 2018. https://www.nrel.gov/docs/fy19osti/72108.pdf.

Barbose, Galen, Naïm Darghouth, Salma Elmallah, Sydney Forrester, Kristina LaCommare, Dev Millstein, Joe Rand, Will Cotton, Stacy Sherwood, and Eric O'Shaughnessy. "Tracking the Sun: Pricing and Design Trends for Distributed Photovoltaic Systems in the United States, 2019 Edition.” Technical Report. Berkeley, CA: Lawrence Berkeley National Laboratory (LBNL), October 2019. https://emp.lbl.gov/sites/default/files/tracking_the_sun_2019_report.pdf.

Bohi, Douglas R. "On the Macroeconomic Effects of Energy Price Shocks." Resources and Energy 13, no. 2 (June 1, 1991): 145-62. https://doi.org/10.1016/0165-0572(91)90012-R.

BPA. "CTA-2045 Water Heater Demonstration Report Including A Business Case for CTA2045 Market Transformation." Technical Report. Bonneville Power Administration (BPA), November 9, 2018. https://www.bpa.gov/EE/Technology/demandresponse/Documents/Demand\%20Response\%20-\%20FINAL\%20REPORT\%20110918.pdf.

Cochran, Jaquelin, Mackay Miller, Owen Zinaman, Michael Milligan, Doug Arent, Bryan Palmintier, Mark O’Malley, et al. "Flexibility in 21st Century Power Systems." Technical Report. Golden, CO: National Renewable Energy Laboratory (NREL), 2014. https://www.nrel.gov/docs/fy14osti/61721.pdf.

CPUC. "California's Distributed Energy Resources Action Plan: Aligning Vision and Action." California Public Utilities Commission (CPUC), May 3, 2017.

https://www.cpuc.ca.gov/uploadedFiles/CPUC_Public_Website/Content/About_Us/Organization /Commissioners/Michael_J._Picker/DER\%20Action\%20Plan\%20(5-3-17)\%20CLEAN.pdf.

Denholm, Paul, Yinong Sun, and Trieu Mai. "Introduction to Grid Services: Concepts, Technical Requirements, and Provisions from Wind." Technical report. National Renewable Energy Laboratory (NREL), January 2019. https://www.nrel.gov/docs/fy19osti/72578.pdf. 
DOE. "Renewable Energy: Distributed Generation Policies and Programs." Resource Collection. Energy.gov, State and Local Solution Center, 2020.

https://www.energy.gov/eere/slsc/renewable-energy-distributed-generation-policies-andprograms.

Faruqui, Ahmad, Sanem Sergici, and Ahmed Sharif. "The Impact of Informational Feedback on Energy Consumption: A Survey of the Experimental Evidence.” Energy, Demand Response Resources: the US and International Experience, 35, no. 4 (April 1, 2010): 1598-1608. https://doi.org/10.1016/j.energy.2009.07.042.

Feldman, David, and Travis Lowder. "Banking on Solar: An Analysis of Banking Opportunities in the U.S. Distributed Photovoltaic Market." Golden, CO: National Renewable Energy Laboratory (NREL), November 2014. https://doi.org/10.2172/1164885.

Feldman, David, Matthew Zwerling, and Robert Margolis. "Q2/Q3 2019 Solar Industry Update." November 12, 2019. https://www.nrel.gov/docs/fy20osti/75484.pdf.

FERC. "Demand Response Compensation in Organized Wholesale Energy Markets [Docket No. RM10-17-000; Order No. 745]." Federal Energy Regulatory Commission (FERC), March 15, 2011. https://www.ferc.gov/EventCalendar/Files/20110315105757-RM10-17-000.pdf.

_. "Distributed Energy Resources: Technical Considerations for the Bulk Power System." Staff Report, February 2018. https://www.ferc.gov/CalendarFiles/20180215112833-derreport.pdf.

—. "Electric Storage Participation in Markets Operated by Regional Transmission Organizations and Independent System Operators [Docket Nos. RM16-23-000; AD16-20-000; Order No. 841].” Federal Energy Regulatory Commission (FERC), February 15, 2018. https://www.ferc.gov/whats-new/comm-meet/2018/021518/E-1.pdf.

"Participation of Distributed Energy Resource Aggregations in Markets Operated by Regional Transmission Organizations and Independent System Operators; Notice Inviting PostTechnical Conference Comments.” Docket No. RM18-9-000. Federal Energy Regulatory Commission (FERC), May 4, 2018.

https://www.federalregister.gov/documents/2018/05/04/2018-09455/participation-of-distributedenergy-resource-aggregations-in-markets-operated-by-regional.

FERC v. Electric Power Supply Assn., No. 14-840 (577 U.S.___ January 25, 2016).

Gyamfi, Samuel, Susan Krumdieck, and Tania Urmee. "Residential Peak Electricity Demand Response: Highlights of Some Behavioural Issues." Renewable and Sustainable Energy Reviews 25 (September 2013): 71-77. https://doi.org/10.1016/j.rser.2013.04.006.

Hale, Elaine, Lori Bird, Rajaraman Padmanabhan, and Christina Volpi. "Potential Roles for Demand Response in High-Growth Electric Systems with Increasing Shares of Renewable Generation." Technical Report. Golden, CO (United States): National Renewable Energy Laboratory (NREL), December 2018. https://www.nrel.gov/docs/fy19osti/70630.pdf. 
Heeter, Jenny, Jeffrey J. Cook, and Jennifer Sauer. "Existing and Potential Corporate Off-Site Renewable Procurement in the Southeast." Technical Report. Golden, CO: National Renewable Energy Laboratory (NREL), February 2019. https://www.nrel.gov/docs/fy19osti/72003.pdf.

Holland, Stephen P., and Erin T. Mansur. "The Short-Run Effects of Time-Varying Prices in Competitive Electricity Markets." The Energy Journal 27, no. 4 (2006): 127-55.

ICF Inc., and DOE. "U.S. DOE Combined Heat and Power Installation Database," 2016. https://doe.icfwebservices.com/chpdb/.

Kellison, Ben, Elta Kolo, Isaac Maze-Rothstein, Kelly McCoy, Francesco Menonna, and Fei Wang. “Grid Edge Quarterly Executive Briefing: Q1 2020.” Market Report. Wood Mackenzie Power \& Renewables, Grid edge analyst team, January 2020.

McAnany, James. "2019 Demand Response Operations Markets Activity Report: April 2020." PJM Demand Side Response Operations, April 6, 2020. https://www.pjm.com/-/media/marketsops/dsr/2019-demand-response-activity-report.ashx?la=en.

NERC. "2019 Long-Term Reliability Assessment.” Atlanta, GA: North American Electric Reliability Corporation (NERC), 2019.

https://www.nerc.com/pa/RAPA/ra/Reliability\%20Assessments\%20DL/NERC_LTRA_2019.pdf.

Newcomb, James, Virginia Lacy, Lena Hansen, and Mathias Bell. "Distributed Energy Resources: Policy Implications of Decentralization." The Electricity Journal 26, no. 8 (October 1, 2013): 65-87. https://doi.org/10.1016/j.tej.2013.09.003.

NYISO. "Distributed Energy Resources Roadmap for New York's Wholesale Electricity Markets." New York Independent System Operator (NYISO), January 2017. https://www.nyiso.com/documents/20142/2261851/2017-Distributed-Energy-ResourcesRoadmap.pdf/9afac12f-6d55-7855-2689-c377b0577304.

PJM Interconnection. "Demand Response Strategy.” PJM Interconnection, June 28, 2017. http://www.pjm.com/ /media/library/reports-notices/demand-response/20170628-pjm-demandresponse-strategy.ashx.

Roozbehani, M., M. A. Dahleh, and S. K. Mitter. "Volatility of Power Grids Under Real-Time Pricing." IEEE Transactions on Power Systems 27, no. 4 (November 2012): 1926-40. https://doi.org/10.1109/TPWRS.2012.2195037.

Russell, Christopher. "Efficiency and Innovation in U.S. Manufacturing Energy Use." National Association of Manufacturers and the Alliance to Save Energy, 2004. https://www.energy.gov/sites/prod/files/2014/05/f15/energy-nam.pdf.

Scott, Janea A. "California Electric Vehicle Vision." Presented at the Maximizing Distributed Energy Resource Value for All Stakeholders, Workshop held at the National Renewable Energy Laboratory, Golden, CO (United States), May 29, 2019. 
Sullivan, Michael J., Terry Vardell, and Mark Johnson. "Power Interruption Costs to Industrial and Commercial Consumers of Electricity." IEEE Transactions on Industry Applications 33, no. 6 (1997): 1448-1458.

Wilkins, Robert L. National Association of Regulatory Utility Commissioners v. Federal Energy Regulatory Commission, No. 19-1142 (United States Court of Appeals for the District of Columbia Circuit July 10, 2020).

Wood Mackenzie P\&R, and ESA. "U.S. Energy Storage Monitor: 2018 Year in Review and Q1 2019 Full Report.” Market Report. Wood Mackenzie Power \& Renewables, Energy Storage Association (ESA), March 2019. 